\title{
Politeness and Language
}

Penelope Brown, Max Planck Institute of Psycholinguistics, Nijmegen, The Netherlands

(c) 2015 Elsevier Ltd. All rights reserved.

\begin{abstract}
This article assesses the advantages and limitations of three different approaches to the analysis of politeness in language: politeness as social rules, politeness as adherence to an expanded set of Gricean Maxims, and politeness as strategic attention to 'face.' It argues that only the last can account for the observable commonalities in polite expressions across diverse languages and cultures, and positions the analysis of politeness as strategic attention to face in the modern context of attention to the evolutionary origins and nature of human cooperation.
\end{abstract}

\section{What Is Politeness?}

If, as many have claimed, language is the trait that most radically distinguishes Homo sapiens from other species, politeness is the feature of language use that most clearly reveals the nature of human sociality as expressed in speech. Politeness is essentially a matter of taking into account the feelings of others as to how they should be interactionally treated, including behaving in a manner that demonstrates appropriate concern for interactors' social status and their social relationship. Politeness - in this broad sense of speech oriented to an interactor's public persona or 'face' - is ubiquitous in language use. Since, on the whole, taking account of people's feelings means saying and doing things in a less straightforward or more elaborate manner than when one is not taking such feelings into consideration, ways of being polite provide probably the most pervasive source of indirectness, reasons for not saying exactly what one means, in how people frame their communicative intentions in formulating their utterances.

There are two quite different kinds of feelings to be attended to, and therefore there are two distinct kinds of politeness. One kind arises whenever what is about to be said may be unwelcome, prompting expressions of respect, restraint, avoidance ('negative politeness'). Another arises from the fact that longterm relationships with people can be important in taking their feelings into account, prompting expressions of social closeness, caring, and approval ('positive politeness'). There are many folk notions for these kinds of attention to feelings including courtesy, tact, deference, demeanor, sensibility, poise, discernment, rapport, mannerliness, urbanity, as well as for the contrasting behavior - rudeness, gaucheness, social gaffes, and for their consequences - embarrassment, humiliation. Such terms label culture-specific notions invested with social importance, and attest both to the pervasiveness of notions of politeness and to their cultural framing.

\section{How Can We Account for Politeness?}

Since politeness is crucial to the construction and maintenance of social relationships, politeness in communication goes to the very heart of social life and interaction; indeed it is probably a precondition for human cooperation in general. Politeness phenomena have therefore commanded interest from theorists in a wide range of social sciences. Three main classes of theoretical approach to the analysis of politeness in language can be distinguished.

1. Politeness as social rules. To the layman, politeness is a concept designating 'proper' social conduct, rules for speech and behavior stemming generally from high-status individuals or groups. In literate societies such rules are often formulated in etiquette books. These 'emic' (culturespecific) notions range from polite formulae like please and thank you, the forms of greetings and farewells, etc., to more elaborate routines for table manners, deportment in public, or the protocol for formal events. Politeness is conventionally attached to certain linguistic forms and formulaic expressions, which may be very different in different languages and cultures. This is how the 'person on the street' tends to think about politeness, as inhering in particular forms of words.

Some analytical approaches to politeness are formulated in terms of the same sorts of culture-specific rules for doing what is socially acceptable, for example, the work by Ide and others on Japanese politeness as social indexing or 'discernment' (see Watts et al., 1992). In these approaches, politeness is a matter of social norms, and inheres in particular linguistic forms when used appropriately as markers of pre-given social categories. This approach is most appropriate for fixed aspects of language use - the more or less obligatory social marking of relatively unalterable social categories.

2. Politeness as adherence to Politeness Maxims. An alternative approach takes the position that the linguistic forms of politeness are not a matter of arbitrary convention but are motivated by general principles. During the 1970s this perspective was formulated in linguistic pragmatics in Gricean terms, with politeness seen as a set of social conventions coordinate with Grice's Cooperative Principle for maximally efficient information transmission ('Make your contribution such as required by the purposes of the conversation at the moment'), with its four 'Maxims' of Quality, Quantity, Relevance, and Manner (see Pragmatics, Linguistic). Lakoff (1973) suggested that three 'rules of rapport' underlie the choice of linguistic expression, rules which can account for how speakers deviate from directly expressing meanings. Choice among these three pragmatic rules ('Don't impose, 'Give options, 'Be friendly') gives rise to distinct communicative styles. Leech's more detailed 
proposal (1983) is in the same vein. Complementary to Grice's Cooperative Principle, Leech postulates a Politeness Principle - 'Minimize the expression of impolite beliefs,' with the six Maxims of Tact, Generosity, Approbation, Modesty, Agreement, and Sympathy. As with Grice's Maxims, deviations from what is expected give rise to inferences. Cross-cultural differences derive from the different importance attached to particular maxims.

The conversational maxim approach shares with the social norm approach the emphasis on codified social rules for minimizing friction between interactors, and the view that deviations from expected levels or forms of politeness carry a message.

3. Politeness as face management. A more sociological perspective places 'face work' at the core of politeness. Goffman (1967) considered politeness as an aspect of interpersonal ritual, central to public order. He defined face as an individual's publicly manifest self-esteem, and proposed that social members have two kinds of face requirements: positive face, or the want for approval from others, and negative face, or the want not to offend others. Attention to these face requirements is a matter of orientation to Goffman's "diplomatic fiction of the virtual offense, or worst possible reading" (Goffman, 1971: 138ff), the working assumption that face is always potentially at risk, so that any interactional act with a social-relational dimension is inherently face-threatening and needs to be modified by appropriate forms of politeness.

\section{Universal Principles of Politeness}

Brown and Levinson (1987, henceforth B\&L) introduced a new perspective by drawing attention to the detailed parallels in the construction of polite utterances across widely differing languages and cultures, and arguing that universal principles underlie the construction of polite utterances. The parallels they noted are of two sorts: how polite utterances are linguistically constructed, and how the polite expression of utterances is modified in relation to social characteristics of the interlocutors and the situation. At least three social factors are involved in deciding how to be polite: (1) one tends to be more polite to social superiors; (2) one tends to be more polite to people one doesn't know. In the first case, politeness tends to go one way upwards (the superior is less polite to an inferior); in the second, politeness tends to be symmetrically exchanged. In addition, (3) in any culture there are norms and values affecting the degree of imposition or unwelcomeness of an utterance, and one tends to be more polite for more serious impositions. In language there are also detailed parallels, with the linguistic structures for realizing particular kinds of politeness showing remarkable similarities across unrelated languages. The politeness of solidarity is characterized, for example, by use of intensifiers, in-group identity markers and address forms, exaggerated intonation patterns, and forms for emphasizing agreement and avoiding disagreement. Avoidance-based politeness is characterized by forms expressing self-effacement, formality, restraint, deference, with the use of honorifics, hedges, indirect speech acts, and impersonalizing mechanisms like pluralization of pronouns, nominalization, and passive. All of these involve elaborating the expression of communicative intent in specific ways that deviate from direct Gricean communication.

Why then are these kinds of detailed parallels across languages and cultures to be found in the minutiae of linguistic expression in socially analogous contexts? Explanations in terms of arbitrary social norms or rules can account for politeness in a particular social group, but not for the cross-cultural patterns, which seem to require a strategic account in terms of what people generally are trying to do when they are being polite. B\&L proposed that such deviations from Gricean efficient communication are motivated by the universal human assumption that interactors have 'face,' in the form of desires for the interactional acknowledgment of their social persona. Following Goffman, they posited two kinds of face: positive face desires for affirmation and social closeness, and negative face desires for separation, personal territory, and freedom from unexpectable impositions. These give rise to two styles of politeness - one addressed to ratifying the personality of the interlocutor (positive or solidarity politeness), and the other designed to mitigate or minimize impositions (negative or respect politeness).

B\&L (1987) proposed an abstract model of politeness wherein human actors are endowed with two essential attributes: face and rationality. Face consists of two specific kinds of wants: positive face (i.e., the desire to be approved of, admired, liked, validated), and negative face (the desire to be unimposed upon, unimpeded in one's actions). The second ingredient in the model - rationality - provides for the ability to reason from communicative goals to linguistic means that would achieve these goals. From these two assumptions - face and rationality - and the assumption that speakers mutually know that all speakers have these two attributes, B\&L developed a model of how speakers construct - and interpret - polite utterances in different contexts on the basis of assessments of three social factors: the relative power $(\mathrm{P})$ of speaker and addressee, their social distance (D), and the intrinsic ranking (R) of the face-threateningness of an imposition. $\mathrm{P}, \mathrm{D}$, and $\mathrm{R}$ are seen as abstract social dimensions indexing kinds of social relationship ( $P$ and $D)$ and cultural values and definitions of impositions or threats to face $(\mathrm{R})$.

B\&L (1987) argued that the actions people do when talking with one another - for example, requesting, informing, offering, complaining - have implications for each others' face, and they identified a wide array of speech act types that have the potential to threaten face: 'face-threatening acts' or FTAs. They distinguished five general types of strategies of politeness, ranging from avoiding an FTA altogether, to carrying it out but 'off record' (indirectly). On-record realization of an FTA can be done without any redressive action at all ('baldly'). It may be carried out with positive redress, which is essentially approach based, addressing the hearer's positive face wants by emphasizing closeness and solidarity. Politeness may also be carried out with negative redress, which is essentially avoidance based, addressing negative face wants for distance, deference, and freedom from impositions. Speakers are assumed to choose the linguistic framing of their utterance from this set of strategic possibilities according to the weightiness of the FTA, which is assessed with reference to the three contextually dependent social factors P, D, and R. For low levels of FTA threat, bald-on-record or positive politeness is most 
appropriate and cost effective; for higher levels, negative politeness is required; for the highest threats, indirectness is the safe option.

The claim, then, is that, however culturally variable the kinds of social relationship and kinds of face threat might be, underlying them are human attributes (face, means-ends reasoning abilities) and pan-cultural social dimensions (relative power, social distance, ranking of face-threateningness) which universally go into the reckoning and the interpretation of strategic language choice, and hence one can derive the cross-cultural similarities in choice of linguistic realizations of politeness strategies that empirically seem to be in evidence. B\&L (1987) claimed further that this model of politeness universals could be applied in particular cultural settings as an ethnographic tool for analyzing the quality of social relationships. Stable social relationships are characterized in part by stable patterns of language use, which may distinguish particular societies or social groups. Analyzing these stable patterns (for example, the distribution of $\mathrm{T} / \mathrm{V}$ pronoun usage across individuals and social groups) can reveal important aspects of social relationships and their changes over time.

\section{Critiques of the B\&L Politeness Model}

The goal of B\&L to formulate a cross-culturally applicable 'etic' set of concepts in terms of which politeness can be analyzed in 'emic' terms for any particular society was ambitious. Etic analytical concepts are drawn from a universal set, defined from outside a particular cultural perspective and used to compare behavioral or linguistic systems across different cultural groups, in contrast to emic ones which are meaningful within a specific culture and are used to describe a system in its own terms. Critics of the B\&L model reveal several major points of contention about whether it is legitimate at all to generalize across cultural systems and, if so, how a theory of politeness should be formulated.

\section{The Universality of Face}

Many critics have challenged B\&L's formulation (via Goffman and Radcliffe-Brown) of positive and negative face wants as a valid way of conceptualizing the universal underpinnings of politeness. Negative face, in particular, considered as wants for freedom from imposition, appears entirely too embedded in Western individualism to sit well with conceptions of face in some other (e.g., east Asian) cultures. In part, this is due to a misconstrual: in the B\&L model, face wants are abstract, they do not necessarily correspond clearly to conscious emic notions. What B\&L (1987) claimed is that underlying diverse folk notions is a core of two interactionally relevant wants (for ratification, and freedom from imposition) which seem to be crossculturally applicable, as desires concerning one's public selfimage in the context of the moment which are assumptions oriented to in interaction. Other theorists (e.g., O'Driscoll, 1996; Arundale, 1999) have argued for notions of positive/negative face that are even more abstract, in terms of merging/individuation or closeness/separation, as the universal heart of politeness.

Challenges to the universality of the model also extend to the proposed hierarchy of increasing politeness (from bald-on-record to positive to negative to indirectness). Assessments of the $\mathrm{P}, \mathrm{D}$, and $\mathrm{R}$ factors are situationally and culturally very variable; it is possible to accumulate different strategies in one utterance and to balance elements of negative politeness with positive politeness in one act, and indirectness is not always seen as the most polite option. These observations have led some researchers to argue against the possibility of identifying any kind of universal basis for polite behavior; politeness is simply incommensurate across societies. Those who take this extreme relativistic line can have no explanation for the observable cross-cultural parallels in patterns of language use, for how people manage (sometimes) to understand others from culturally different backgrounds, or for cross-linguistic parallels in the diachronic sources of honorifics from politeness strategies.

\section{Politeness as Communicated or Taken for Granted}

In contrast with rule-based approaches, B\&L (1987) insist that politeness inheres not in words or in sentences per se, but in utterances uttered in a context, by virtue of the successful communication of a polite attitude or intention. Polite utterances are not necessarily communicating 'real' feelings about anothers' social persona, but expressing contextually expected concern for face. This concern is an 'implicature,' an inference of polite intentions, not a feature inextricably attached to particular linguistic forms. Politeness is ascribed to a speech act, or to an interactional move (if you prefer), not to a strategy or its linguistic realization perse.

In other approaches (for example, Fraser's (1990) 'conversational contract,' Watts et al.'s (1992) 'politic behavior'), politeness is taken to be the expected background to interaction; it is normally not communicated but consists in following expectations as to appropriate behavior.

\section{Broad versus Narrow Scopes for Politeness Theory}

A narrower view takes politeness to be strategic orientation to potential face threats; there are some situations (e.g., taskoriented ones) where politeness may be subsumed to other goals, and there are many reasons for being indirect in speech other than politeness (e.g., humor, irony, rhetorical force). Many motivations other than politeness guide human behavior. A more inclusive view sees politeness as orientation to the social-relationship dimension of every interaction, with attention to face taken to be an omnipresent necessity. The whole continuum from extreme politeness through a quite neutral level of politeness (maintaining the status quo, 'discernment') to rudeness (outright intentional threat) then needs to be brought into the theory.

\section{Politeness from the Point of View of the Individual, the Dyad, or the Social Group}

The B\&L model takes the interacting dyad as its unit; it is about how interlocutors make inferences of politeness from one another's deviations from Gricean efficient communication, and how stable patterns of strategies characterize dyadic interaction, providing an index to the quality of the social relationship. Many politeness strategies are quintessential examples of 'intersubjective perspective-taking' - putting yourself in the others' position. A major goal of B\&L (1987) was to insist on the centrality of social interaction as a significant level of social life, intermediate between the individual and society, where social/cultural facts (status, role, values, norms, rights, and obligations) are integrated with individual ones (goals, plans, and strategies). 
Yet the Gricean foundation of the theory and the speech-actbased formulation of the B\&L strategies have made many see the model as purely psychological (how a speaker calculates how to frame an utterance). Arundale (1999), for example, argues instead for a theory of how face is jointly constituted in ongoing interaction. In fact, we need both perspectives: face is indisputably interactionally created, negotiated, and manipulated. Nevertheless, it can be considered from the point of view of the individual speaker or hearer (as B\&L do in their production/comprehension model), or of the society or social group (as 'face constituting theory' and most sociolinguists do).

\section{The Indeterminacy Problem}

B\&L (1987) proposed their model as a concrete discovery method for analyzing social relationships in any society by studying members' speaking practices. However, the usefulness of this model as an ethnographic tool is undermined by a number of complexities that arise when examining naturally occurring language usage data. The problems of mixing strategies in a single utterance and ordering of strategies across utterances are compounded by the indeterminacy of contextdependent $\mathrm{P}, \mathrm{D}$, and $\mathrm{R}$ assessments and by difficulties of establishing whether an utterance is intended to be taken as ironic, joking, or teasing. All of these make it hard to code levels of politeness in any concrete situation and to assess how different expressions interact to produce a composite message in an utterance. These are problems with any theory in terms of actors' intentions when applied to empirical data; as both interactors and conversation analysts know, it is not always possible to be certain what interlocutors' intentions are at a particular point in natural interaction. The B\&L model of politeness as originally formulated clearly needs elaboration and revision.

\section{New Directions in Research on Politeness}

The intellectual climate of research has changed radically in the four decades since the B\&L model was fostered at the University of California, Berkeley, in the early 1970s. Since then an enormous amount of research has addressed politeness from a variety of perspectives, in work coming from all the social sciences that have an interest in social interaction. Empirical studies of politeness have greatly increased the amount of information we have about social interactional styles in different contexts and different societies. Yet the research emphasis in work on politeness has been largely on cross-cultural differences in politeness, with little attention addressed to the cross-linguistic and crosscultural parallels which motivated the theory. Indeed, very few studies provide the crucial kinds of evidence necessary to test the universality of any theory of politeness, namely, for a range of particular societies, an 'ethnography of speaking' providing evidence of naturally occurring language usage across a wide range of different contexts, showing how politeness is interactionally modulated in relation to local social factors in that society.

Researchers, impressed by different cultural views of face, propriety, conviviality, and the individual, have generally preferred to study culture-specific patterns of language use. Yet the significance of politeness lies far beyond the culturespecific rules of appropriate behavior and speech that seem so salient to members of the culture. This wider significance lies in the fact that by regular patterns of language choice humans interactively construct their social relationships. Research in this area therefore needs to be based in a theory of social interaction that takes into account both our common human nature and ability to communicate cross-culturally, and the cultural differences which can sometimes lead us to misunderstand one another. Despite its shortcomings, the B\&L model retains its hold on research on politeness largely because it provides a coherent set of concepts for analytically dissecting polite speech in different societies and contexts. It is also the only theory that begins to provide an account for the detailed cross-cultural parallels in polite speech.

In the new millenium, research agendas and priorities have changed. The study of social interaction has turned to focus on the interactional foundations of language, its cognitive underpinnings, and its instantiation in the brain. Research continues on the sociocultural contexts of language use, with a major emphasis on face as co-constructed in interaction and on the sequential development of this interactional process, with impoliteness as well as politeness as the object of enquiry. A corresponding emphasis on the sequentially developing contexts for face and related politeness issues (preference structures, entitlement, 'ownership' of knowledge, 'fairness') appears in the field of Conversation Analysis, for example, in Pomerantz and Heritage (2013), Lerner (1996), Heinemann (2006), Curl and Drew (2008), Heritage and Raymond (2005), and Heritage (2013). There is also an increasing trend toward the comparative study of naturally occurring interaction from a conversation analytic perspective (Sidnell, 2009), as well as new theoretical approaches to the study of cultural models (e.g., Strauss, 2004) and of human social relations - for example, Agha's (2007) view of social relations as created through language use shaped by reflexive models of social life. All of these developments can be expected to feed into our understanding of politeness.

Another new direction is the emerging emphasis on the cooperative basis of human sociality and on the interactional underpinnings to language, its evolution, and its ethological base; Goody (1995), Enfield and Levinson (2006), Tomasello (2008, 2009), and Stivers et al. (2009) can be mentioned here. There are recent investigations into the cognitive and brain underpinnings to interaction (e.g., De Ruiter et al., 2010; Noordzij et al., 2009, 2010), work which forms a new context within which the search for universal bases for politeness can be pursued, exploring the cognitive prerequisites for politeness, such as recursive theory of mind, without which the elaborate demonstration of mutual regard would be impossible. This context suggests that the inhibition of aggression, the soothing character of politeness work, and the elaborate interpersonal ritual that politeness represents, may have played a crucial role in the evolution of the specifically human forms of social life and culture, and, indeed, may have been a fundamental factor driving the evolution of human cognition.

\section{Conclusions}

Politeness has attracted an enormous amount of research attention since the 1970s, and continues to be a major focus for research in disciplines concerned with social interaction. 
The study of politeness phenomena can provide insight into widely differing issues; foci of interest correspondingly differ widely. They include, for example, analyses of the sequential development of politeness in natural interaction, the study of cross-cultural pragmatics and misunderstanding, the ethnography of speaking of face and politeness in different cultures and contexts, politeness strategies as providing the stylistic coherence of particular types of interaction (e.g., gender differences in speech style), politeness as a functional motivation for linguistic structure (e.g., honorifics), the social psychology of face management and interpersonal perception, applications of politeness theory to the analysis of formal ritual and to a view of culture as 'rhetoric,' or forms of effective expression.

Research on politeness has, however, been much weaker on the theoretical front. A major limitation is the kinds of data used in analyses. A large proportion of studies take as their data people's conscious evaluations of politeness expressed in sentences, judgments which tend to be both prescriptive and stereotypical. Far fewer studies use as data recordings of situated conversational exchanges to explore how politeness is achieved sequentially in naturally occurring discourse, and only a handful provide the crucial kind of evidence necessary to test the universality of any theory of politeness: for a particular society, an 'ethnography of speaking' providing evidence across different contexts to show how politeness is modulated in relation to social factors ( $\mathrm{P}, \mathrm{D}, \mathrm{R}$, and others) in that society.

The emphasis in research has been largely on cross-cultural differences, with insufficient attention addressed to the crosslinguistic/cross-cultural parallels which tend to be taken for granted when they are not disputed. But politeness has a significance far beyond the $\mathrm{P}^{\prime} \mathrm{s}$ and $\mathrm{Q}$ 's of appropriate behavior and speech. The wider significance of politeness is in the interactional, communicative, day-to-day basis of social life and the conduct of social relationships. Research on politeness needs to be anchored in a theory of social interaction that takes account both of our common human nature and our ability to communicate cross-culturally and of cultural differences which make us sometimes misunderstand one another.

See also: Communicative Competence: Linguistic Aspects; Cooperation: Sociological Aspects; Discourse, Anthropology of; Intercultural Communication: An Anthropological Perspective; Intergroup Relations; Linguistic Anthropology; Pragmatics, Linguistic; Prosocial Behavior and Empathy; Social Psychology; Status and Role, Social Psychology of.

\section{Bibliography}

Agha, A., 2007. Language and Social Relations. Cambridge University Press, Cambridge, UK.

Arundale, R., 1999. An alternative model and ideology of communication for an alternative to politeness theory. Pragmatics 9, 119-153.

Brown, P., Levinson, S.C., 1987[1978]. Politeness: Some Universals in Language Use. Cambridge University Press, Cambridge, UK.

Brown, R., Gilman, A., 1968[1960]. Pronouns of power and solidarity. In: Fishman, J. (Ed.), Readings in the Sociology of Language. Mouton, The Hague, Netherlands, pp. 252-276.
Coulmas, F. (Ed.), 1991. New Perspectives on Linguistic Etiquette. International Journal of the Sociology of Language Mouton de Gruyter, New York; Berlin. P40 I58 no. 91-94.

Culpeper, J., 2011. Impoliteness: Using Language to Cause Offence. Cambridge University Press, Cambridge, UK.

Curl, T., Drew, P., 2008. Contingency and action: a comparison of two forms of requesting. Research on Language and Social Interaction 41 (2), 129-153.

De Ruiter, J.P., Noordzij, M.L., Newman-Norlund, S., Hagoort, P., Levinson, S.C., Toni, I., 2010. Exploring the cognitive infrastructure of communication. Interaction Studies 11, $51-77$.

Dufon, M.A., Kasper, G., Takahashi, S., Yoshinaga, N., 1994. Bibliography on linguistic politeness. Journal of Pragmatics 21, 527-528.

Enfield, N.J., Levinson, S.C. (Eds.), 2006. Roots of Human Sociality. Cambridge University Press, Cambridge, UK.

Fraser, B., 1990. Perspectives on politeness. Journal of Pragmatics 14, 219-236.

Goffman, E., 1967. The nature of deference and demeanor. In: Goffman, E. (Ed.), Relations in Public: Microstudies of the Public Order. Harper and Row, New York.

Goody, E., 1995. Social Intelligence and Interaction. Cambridge University Press, Cambridge, UK.

Goffman, E., 1971. Relations in Public: Microstudies of the Public Order. Basic Books, New York.

Grice, H.P., 1975. The logic of conversation. In: Cole, P., et al. (Eds.), Syntax and Semantics 3: Speech Acts. Elsevier, pp. 41-58.

Heinemann, T., 2006. "Will you or can't you?" Displaying entitlement in interrogative requests. Journal of Pragmatics 38, 1081-1104.

Heritage, J., Raymond, G., 2005. The terms of agreement: indexing epistemic authority and subordination in assessment sequences. Social Psychology Quarterly 68, $15-38$.

Heritage, J., 2013. Epistemics in conversation. In: Stivers, T., Sidnell, J. (Eds.), Handbook of Conversation Analysis. Wiley/Blackwell, London, pp. 370-394.

Ide, S., 1989. Formal forms and discernment: two neglected aspects of linguistic politeness. Multilingua 8 (2/3), 223-248.

Kasper, G., 1990. Linguistic politeness: current research issues. Journal of Pragmatics 14, 193-218.

Lakoff, R., 1973. The logic of politeness or minding your p's and q's. In: Papers from the Ninth Regional Meeting of the Chicago Linguistic Society Chicago, pp. 292-305.

Leech, G., 1983. Principles of Pragmatics. Longman, London.

Lerner, Gene, 1996. Finding "face" in the preference structures of talk-in-interaction. Social Psychology Quarterly 59, 303-321.

Linguistic Politeness Research Group (Ed.), 2011. Discursive Approaches to Politeness. Mouton de Gruyter, Berlin.

Matsumoto, Y., 1988. Reexamination of the universality of face: politeness phenomena in Japanese. Journal of Pragmatics 12, 403-426.

Matsumoto, Y., 1989. Politeness and conversational universals - observations from Japanese. Multilingua 8 (2/3), 207-221.

Noordzij, M., Newman-Norlund, S.E., De Ruiter, J.P., Hagoort, P., Levinson, S.C., Toni, I., 2009. Brain mechanisms underlying human communication. Frontiers in Human Neuroscience 3, 14.1-14.13.

Noordzij, M.L., Newman-Norlund, S.E., De Ruiter, J.P., Hagoort, P., Levinson, S.C., Toni, I., 2010. Neural correlates of intentional communication. Frontiers in Neuroscience 4, E188.

O'Driscoll, J., 1996. About face: a defence and elaboration of universal dualism. Journal of Pragmatics 25, 1-32.

Okamoto, S., 1999. Situated politeness: coordinating honorific and non-honorific expressions in Japanese conversations. Pragmatics 9 (1), 51-74.

Pomerantz, A., Heritage, J., 2013. Preference. In: Stivers, T., Sidnell, J. (Eds.), Handbook of Conversation Analysis. Wiley-Blackwell Press, Hoboken, NJ, pp. 210-228.

Sidnell, J., 2009. Conversation Analysis: Comparative Perspectives. Cambridge University Press, Cambridge, UK.

Stivers, T., Enfield, N.J., Brown, P., Englert, C., Hayashi, M., Heinemann, T., Hoymann, G., Rossano, F., De Ruiter, J.P., Yoon, K.-E., Levinson, S.C., 2009. Universals and cultural variation in turn-taking in conversation. Proceedings of the National Academy of Sciences of the United States of America 106 (26), 10587-10592.

Strauss, C., 2004. Cultural standing in expression of opinion. Language in Society 33 (2), 161-194.

Strecker, I., 1998. The Social Practice of Symbolization. Athlone, London.

Strecker, I., 2010. Ethnographic Chiasmus: Essays on Culture, Conflict and Rhetoric. Lit and Michigan State University Press, Michigan; Berlin.

Tomasello, M., 2009. Why We Cooperate. MIT Press, Cambridge, MA.

Tomasello, M., 2008. Origins of Human Communication. MIT Press, Cambridge, MA.

Tracy, K., 1990. The many faces of facework. In: Giles, H., Robinson, W.P. (Eds.), Handbook of Language and Social Psychology. Wiley, Chichester, UK, pp. 209-226.

Watts, R.J., Ide, S., Ehlich, K. (Eds.), 1992. Politeness in Language. Mouton, Berlin. 